\title{
FLORA DE GRÃO-MOGOL, MINAS GERAIS: RUTACEAE ${ }^{1}$
}

\author{
JOSÉ RUBENS PIRANI
}

Departamento de Botânica, Instituto de Biociências, Universidade de São Paulo, Caixa Postal 11461, 05422-970 - São Paulo, SP, Brasil.

Cowan, R.S. \& Smith, L.B. 1973. Rutáceas. In R. Reitz (ed.) Flora ilustrada catarinense. Herbário Barbosa Rodrigues. Itajaí. Engler, H.G.A. 1874. Rutaceae. In C.F.P. Martius \& A.G. Eichler (eds.) Flora brasiliensis. Frid. Fleischer, Leipzig, vol. 12, pars 2, p. 76-196, tab. 14-39.

Engler, H.G.A. 1986. Rutaceae. In H.G.A. Engler \& K.A.E. Prantl (eds.) Die natürlichen Pflanzenfamilien. Wilhelm Engelmann. Leipzig, ed. 2, vol. 19a, p. 187-359.

Groppo, M., Kallunki, J.A. \& Pirani, J.R. 2005. Synonymy of Hortia arborea with H. brasiliana (Rutaceae) and a new species from Brazil. Brittonia 57(1): 28-34.

KaAstRA, R.C. 1982. Pilocarpinae (Rutaceae). Fl. Neotrop. Monogr. 33: 1-198.

Pirani, J.R. 1989. Flora da Serra do Cipó, Minas Gerais. Rutaceae. Bol. Bot. Univ. São Paulo 11: 109-119.

PIRANI, J.R. 1998. A revision of Helietta and Balfourodendron (Rutaceae, Pteleinae). Brittonia 50(3): 348-380.

PIRANI, J.R. 2002. Rutaceae. In M.G.L. Wanderley, G.J. Shepherd, A.M. Giulietti, T.S.A. Melhem, V. Bittrich \& C. Kameyama (eds.) Flora fanerogâmica do Estado de São Paulo. FAPESP, HUCITEC. São Paulo, vol. 2, p. 281-308.

1. Folhas pinadas ou bipinadas; flores unissexuadas; fruto folículo ou com mericarpos foliculares.

2. Folhas pinadas; planta aculeada; pontos translúcidos (glândulas oleíferas) em toda a lâmina; fruto folículo com 1 semente subglobosa negra.....

$2^{\prime}$. Folhas bipinadas, com pontos translúcidos apenas nas margens dos foliólulos; planta inerme; fruto com 5 mericarpos foliculares, com sementes aladas acastanhadas

Zanthoxylum rhoifolium

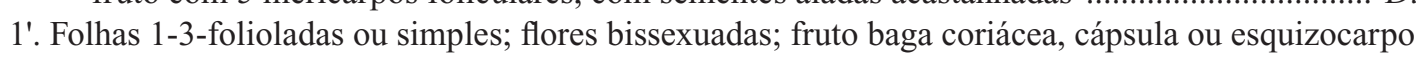

3. Inflorescências corimbiformes terminais, com pedúnculo crasso e reticulado; fruto baga coriácea; folhas simples

3'. Inflorescências paniculadas ou tirsos ou cimóides, alongadas, com pedúnculo delgado e não reticulado; fruto cápsula ou esquizocarpo com samarídeos; folhas 1-3-folioladas.

4. Folhas opostas, 3-folioladas; fruto esquizocarpo com 5 mericarpos alados (samarídeos)

4'. Folhas alternas, 1 ou 3-folioladas; fruto cápsula ou esquizocarpo com 3-5 mericarpos não alados.

5. Lâmina foliar de ápice obtuso a emarginado; botões florais subglobosos; pétalas menores que $7 \mathrm{~mm}$ compr.; fruto cápsula espinescente a muricada

6. Folhas unifolioladas, subglabras; pecíolo 0,3-1 cm compr.; inflorescência pauciflora, ca. $4 \mathrm{~cm}$ compr.; cápsula densamente espinescente Dictyoloma vandellianum 6'. Folhas 3-folioladas, pubescentes; pecíolo 2-6 cm compr.; inflorescência laxa, multiflora, 10-25 cm compr.; cápsula muricada com poucas projeções obtusas, não espinescentes ...... Hortia brasiliana Helietta glaziovii

5'. Lâmina foliar curto a longo-acuminada; botões florais tubulosos; pétalas maiores que $20 \mathrm{~mm}$ compr.;

fruto cápsula lisa ou com 3-5 mericarpos foliculares.

7. Folhas unifolioladas; pétalas unidas em tubo de 18-21 mm compr.; estames férteis 2 ,

7'. Folhas 3-folioladas; pétalas livres, expandidas e reflexas na antese, ca. $20-35 \mathrm{~mm}$ compr.; Esenbeckia estames férteis 5; estaminódios ausentes; fruto com mericarpos conchiformes. Spiranthera odoratissima

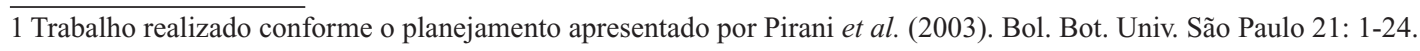




\section{Dictyoloma A.Juss.}

Árvores. Folhas alternas, bipinadas, folíolos com glândulas translúcidas apenas na margem. Inflorescência em ampla panícula corimbiforme terminal. Flores unissexuadas em planta monóica, 5-meras; pétalas livres; estames 5, livres, dotados na base interna dos filetes de um apêndice bífido com margem densamente vilosa, reduzidos nas flores pistiladas; carpelos 5, unidos apenas pelos estiletes, vilosos, muito reduzidos nas flores estaminadas, assentados sobre disco espessado piloso. Fruto esquizocarpo seco com 5 mericarpos foliculares; sementes 3-4 por mericarpo, aladas, muito comprimidas.

1.1. Dictyoloma vandellianum A.Juss., Mém. Mus. Hist. Nat. 12: 499; fig. 24. 1825.

Arvoreta 3-7 m alt. Folhas ca. 20-40 cm compr., tomentosas; raque de $1^{\circ}$ ordem lenhosa; raque de $2^{\circ}$ ordem estreito-alada; foliólulos 5-12 pares por folíolo, discolores, 3-4,5 cm compr., 1-1,8 cm larg., oblongos, ápice obtuso a agudo, base assimétrica. Inflorescência 30-66 cm compr., tomentosa, multiramosa. Flores creme-esbranquiçadas, ca. $8 \mathrm{~mm}$ compr., odoríferas; pétalas oblongas, seríceo-pilosas na região mediana externa, com apículo inflexo; estigma espessado. Mericarpos semi-orbiculares, comprimidos lateralmente, atenuados na base, estipitados, pilosos, introrsamente deiscentes em 2 valvas; sementes com ala larga membranácea e reticulada. (Fig. 1. A-J)

Pirani et al. CFCR 890 (SPF); Simonis \& Cordeiro CFCR 4153 (SPF); Zappi et al. CFCR 12079 (SPF).

Bahia e Minas Gerais até São Paulo, em florestas e formações secundárias. Em Grão-Mogol, ocorre em mata montana e capoeirões. Floresce de fevereiro a abril; frutos maduros em junho e julho.

Nome popular: brauninha.

\section{Esenbeckia Kunth}

Árvores ou arbustos. Folhas alternas ou opostas, simples ou 1-5-folioladas, com pontuações translúcidas (glândulas oleíferas). Inflorescência geralmente em panícula terminal. Flores bissexuadas, geralmente 5-meras, actinomorfas; pétalas livres, membranáceas ou carnosas; estames 5, alternipétalos, anteras ovóides geralmente cedo decíduas; ovário deprimido, circundado pelo disco intra-estaminal anular, 5-carpelar, superfície geralmente irregular ou muricada; óvulos (1)2 por lóculo, colaterais. Fruto cápsula lenhosa, geralmente muricada, deiscência simultaneamente septicida e loculicida, originando 4-5 mericarpos bivalvares, endocarpo claro e elástico (deiscência explosiva); sementes 1-2 por lóculo.

\subsection{Esenbeckia grandiflora Mart., Nov. Gen. sp. pl. 3: 85 .} 1831.

Arvoreta até $7 \mathrm{~m}$ alt., bissexuais. Folhas unifolioladas, alternas a subopostas, glabras, elípticas a obovadas a oblanceoladas, ápice geralmente obtuso, margem revoluta, base atenuada, opacas, 3-12 cm compr., 1,2-5 cm larg.; pecíolo 0,3-1 cm compr., transversalmente fissurado, espessado e geniculado no ápice. Inflorescência ereta, pauciflora, ca. $4 \mathrm{~cm}$ compr. Cálice ferrugineo-tomentoso; pétalas creme-esverdeadas a vináceas, patentes, tomentosas na região mediana externa; estilete ca. $2 \mathrm{~mm}$ compr. Cápsula subglobosa, castanho-escura, coberta de projeções espiniformes piramidais, glabra, 1,5-2 cm compr. (Fig. 1. K-M).

Hatschbach 41253 (MBM, SPF); Hatschbach \& Nicolack 54158 (MBM, SPF); Mello-Silva \& Cordeiro CFCR 10055 (SPF); Pirani et al. CFCR 871 (NY, SPF); Taylor et al. 1510 (K, SPF); Zappi et al. CFCR 12026 (SPF).

Ampla distribuição na América do Sul, mas concentrada no Sul, Sudeste e Nordeste do Brasil, principalmente em florestas pluviais costeiras e nas matas do interior. Em Grão-Mogol, é encontrada como ciófita, nas matas ripárias e nas baixadas da vegetação transicional cerrado-carrasco, florescendo em janeiro e frutificando em novembro, abril e maio. Embora as populações de Grão-Mogol tenham folhas, pecíolos e frutos reduzidos, as flores com perianto pubescente levam à identificação como E. grandiflora Mart. subsp. grandiflora.

Nome popular: guaxupita.

2.2. Esenbeckia irwiniana Kaastra, Acta Bot. Neerl. 26(6): 473. 1977.

Arbusto a arvoreta 1-3 m alt. Folhas alternas, trifolioladas, pubescentes; pecíolo canaliculado, 2-6 cm compr.; folíolos distintamente peciolulados, obovados a elípticos, ápice obtuso a emarginado, margem revoluta, base arredondada a atenuada, assimétrica nos folíolos laterais, face adaxial lustrosa e glabrescente, a abaxial opaca e densamente pubescente principalmente na nervura mediana, 3-10 cm compr., 2-5 cm larg., nervuras laterais salientes. Panícula ereta, laxa, multiflora, 10-25 cm compr., pubescente. Cálice externamente alvo-pubescente; pétalas alvas a creme, pubescentes; disco vináceo; estilete 3-5 $\mathrm{mm}$ compr. Cápsula subglobosa, esparsamente muricada com projeções obtusas, mais adensadas na base, cada carpelo com uma apófise dorso-apical ascendente, esparsamente pubescente, 1,5-2 cm compr. (Fig. 1. N-R) 


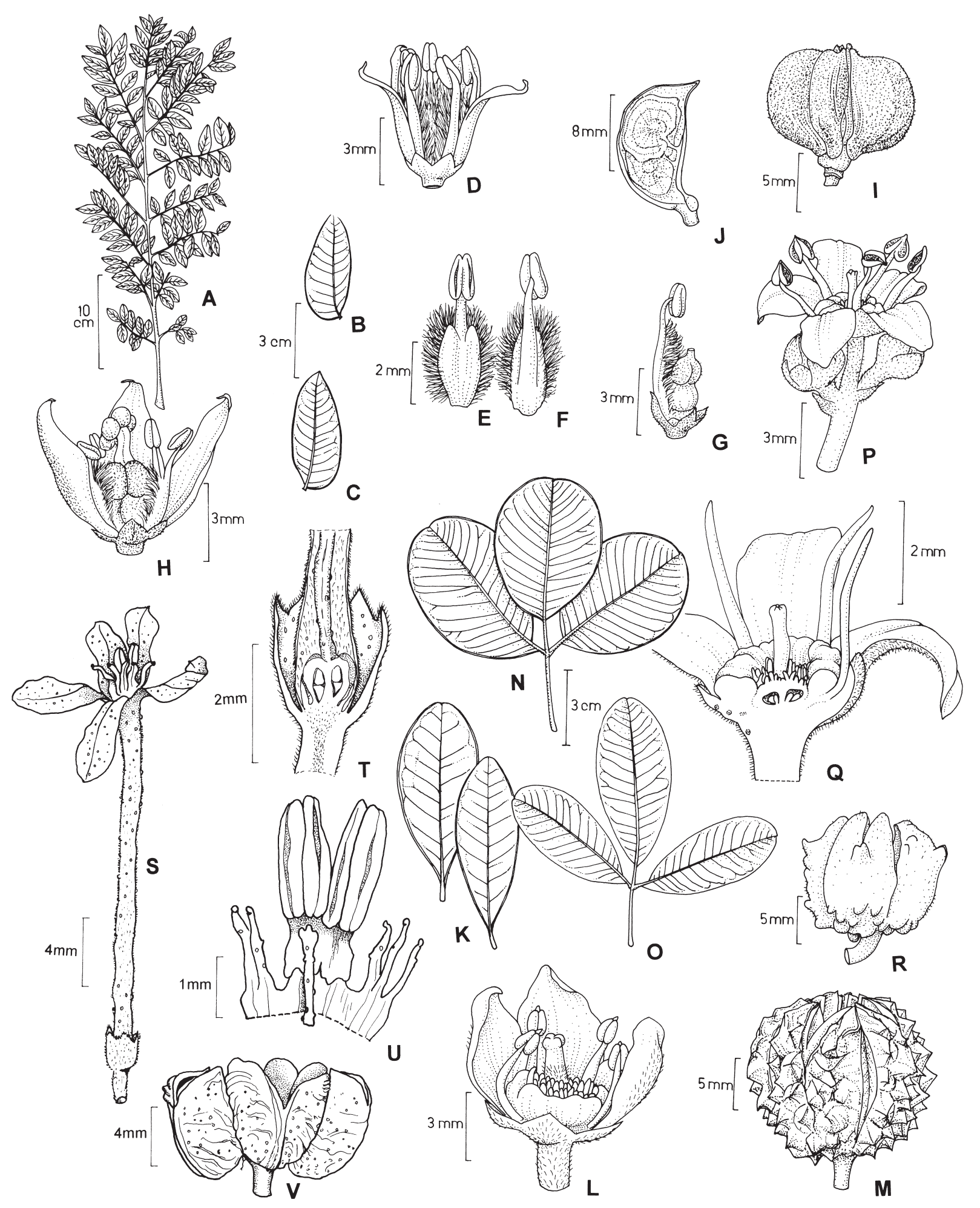

Fig. 1. RUTACEAE: A-J. Dictyoloma vandellianum: A. Folha; B, C. Foliólulos, face adaxial; D. Flor estaminada sem uma pétala; E, F. Estame, vista adaxial e abaxial; G. Estame e pistilódio sobre disco; H. Flor pistilada, removidas duas pétalas; I. Fruto imaturo com 5 carpídios; J. Carpídio, corte longitudinal, mostrando 2 sementes aladas. K-M. Esenbeckia grandiflora: K. Folhas, face abaxial; L. Flor sem duas pétalas e um estame; M. Cápsula na deiscência. N-R. E. irwiniana: N, O. Folhas, face abaxial; P. Parte da inflorescência, com flor terminal em antese e dois botões; Q. Flor, corte longitudinal, as anteras cedo decíduas; R. Cápsula, início de deiscência. S-V. Galipea simplicifolia: S. Flor na antese; T. Base da flor em corte longitudinal expondo o ovário 2-locular circundado pelo disco; U. Ápice do tubo estaminal aberto com 2 anteras e 5 estaminódios; à frente a porção distal do estilete; V. Cápsula na deiscência. 
Furlan et al. CFCR 764 (SPF); Giulietti et al. CFCR 9901 (SPF); Harley et al. CFCR 6502 (K, SPF); Kameyama et al. CFCR 9057 (SPF); Mello-Silva et al. CFCR 9593, 9884 (SPF); Pirani et al. CFCR 12401 (SPF); Simonis \& Cordeiro CFCR 4109 (SPF).
Restrita ao Planalto de Diamantina e à Serra de Grão-Mogol, onde é freqüente heliófita dos carrascos de solo arenoso-pedregoso, rara no campo rupestre. Foi coletada com flores de novembro a fevereiro e em julho, e com frutos de fevereiro a abril e em julho.

\section{Galipea Aubl.}

Arvoretas ou arbustos. Folhas alternas, (1)3-folioladas, com pontuações translúcidas (glândulas oleíferas), freqüentemente com acúmen emarginado. Inflorescências geralmente tirsóides terminais a axilares (subterminais), pauci a multifloras. Flores 5-meras, bissexuadas, com glândulas globosas salientes em quase todas as partes; cálice gamossépalo, persistente; corola tubulosa, zigomorfa; pétalas 5, imbricadas, patentes, 3 inferiores, 2 superiores; androceu com todos os filetes conatos em tubo e este adnato à corola; estames férteis 2, inferiores, anteras oblongas exsertas, conectivo apendiculado na base; estaminódios 3-6, lineares, exsertos; disco urceolado glabro; carpelos 5, conatos; estilete filiforme exserto na antese, estigma capitado; óvulos 2 por lóculo, superpostos. Fruto cápsula lenhosa loculicida e parcialmente septicida, geralmente carenada dorsalmente; endocarpo amarelado livre do mesocarpo e abrindo elasticamente; semente 1 por lóculo, ovóide a reniforme.

3.1. Galipea simplicifolia (Nees \& Mart.) Engl. in Mart., Fl. bras. 12(2): 98.1874.

Arbusto a arvoreta 0,7-1 m alt Folhas alternas a ocasionalmente subopostas, 1-foliolate; pecíolo plano a canaliculado, 0,3-2 cm compr.; lâmina elíptica a estreito-elíptica, (4) 5,5-12 cm compr., (1,5) 2-4 cm larg., base atenuada, ápice agudo a curto-acuminado, conspicuamente emarginado, cartácea, glabra ou com tricomas curtos na nervura mediana. Inflorescência um cimóide terminal, ereto, paucifloro, 3-10 cm compr., com florescências parciais dicasiais (címulas 3-floras). Cálice urceolado, creme-esverdeado, pubescente na face externa; tubo da corola 18-21 mm compr., 1-1,5 mm diâm, densamente apresso-pubescente , lobos 5-7 mm compr., imbricados no botão, recurvados na antese, pubescentes; tubo dos filetes densamente coberto de tricomas longos; anteras ca. $2.5 \mathrm{~mm}$ compr., glabras, cada uma com base estéril e dotada de um apêndice, conatas entre si pelas margens e pelos apêndices; estaminódios livres no ápice, 2-3 mm compr.; disco ondulado na margem, glabro, menor que o ovário glabro; estilete ca. 19-20 mm compr. na antese, depois alongado até $22 \mathrm{~mm}$, glabro, densamente glanduloso. Cápsula subglobosa, 5-lobada e 5-carenada, 7-8 x 12-14 mm, glabra; endocarpo liso, ocráceo, elasticamente deiscente; semente 1 por lóculo, reniforme a ovóide. (Fig. $1 \mathrm{~S}-\mathrm{V}$ ).

Carvalho 926 (BHCB, SPF); Pirani et al. 5367 (K, MBM, NY, R, SP, SPF).

Espécie distribuída do centro da Bahia ao nordeste e leste de Minas Gerais, em matas semideciduais e matas ripárias. Em Grão-Mogol, foi encontrada em mata ciliar margeando o Rio Itacambiruçu, com flores em março.

\section{Helietta Tul.}

Arvoretas. Folhas opostas ou subopostas, trifolioladas, com pontuações translúcidas; folíolos geralmente sésseis. Inflorescência em tirso terminal, ramos opostos. Flores bissexuadas, 4-5-meras, actinomorfas; sépalas quincunciais; pétalas livres, imbricadas no botão; estames 4-5, livres, alternipétalos, anteras bitecas, ovóides, versáteis; disco intra-estaminal cupular, 4-5lobado; ovário depresso-globoso, 4-5-carpelar e locular; óvulos 2 por lóculo, colaterais, pêndulos; estilete 1, estigma capitado. Fruto esquizocarpo com (3)4-5 mericarpos samaróides, separando-se na maturidade da base para o ápice, secos, com ala dorsal ascendente; semente 1 por samarídeo.

\subsection{Helietta glaziovii (Engl.) Pirani, Brittonia 50(3): 369. 1998.}

Arvoreta 1,5-4(-7) m alt. Folhas pubescentes quando jovens mas geralmente completamente glabrescentes; pecíolo 0,5-2(-3) cm compr., canaliculado adaxialmente; folíolos 3, cartáceos a subcoriáceos, subsésseis a sésseis, estreito-obovados a oblanceolados, margem levemente revoluta, ápice obtuso a emarginado, base assimétrica nos folíolos laterais, 3,7-8 cm compr., 1,4-3,4 cm larg., nervação broquidódroma saliente. Diplotirso 8-12 cm compr., ramos creme-esverdea- dos, laxos e multifloros; flores (4)5-meras, sépalas suborbiculares verdes, cilioladas; pétalas alvas a creme, oblongas, obtusas, cilioladas; estames exsertos, anteras amarelas; ovário (4)5-lobado, glabro, estilete cilíndrico. Samarídeos glabros, o núcleo seminífero ca. $1 \mathrm{~cm}$ compr., a ala 1,5-1,7 cm compr., 0,9-1,1 cm larg., com nervuras salientes. (Fig. 2. A, B)

Mello-Silva et al. CFCR 9679 (SPF); Pirani \& Mello-Silva CFCR 10861 (SPF); Pirani et al. CFCR 8403 (SPF), CFCR 8878 (K, NY, SP, $\mathrm{SPF})$.

Planalto de Diamantina e Grão-Mogol, em Minas Ge- 


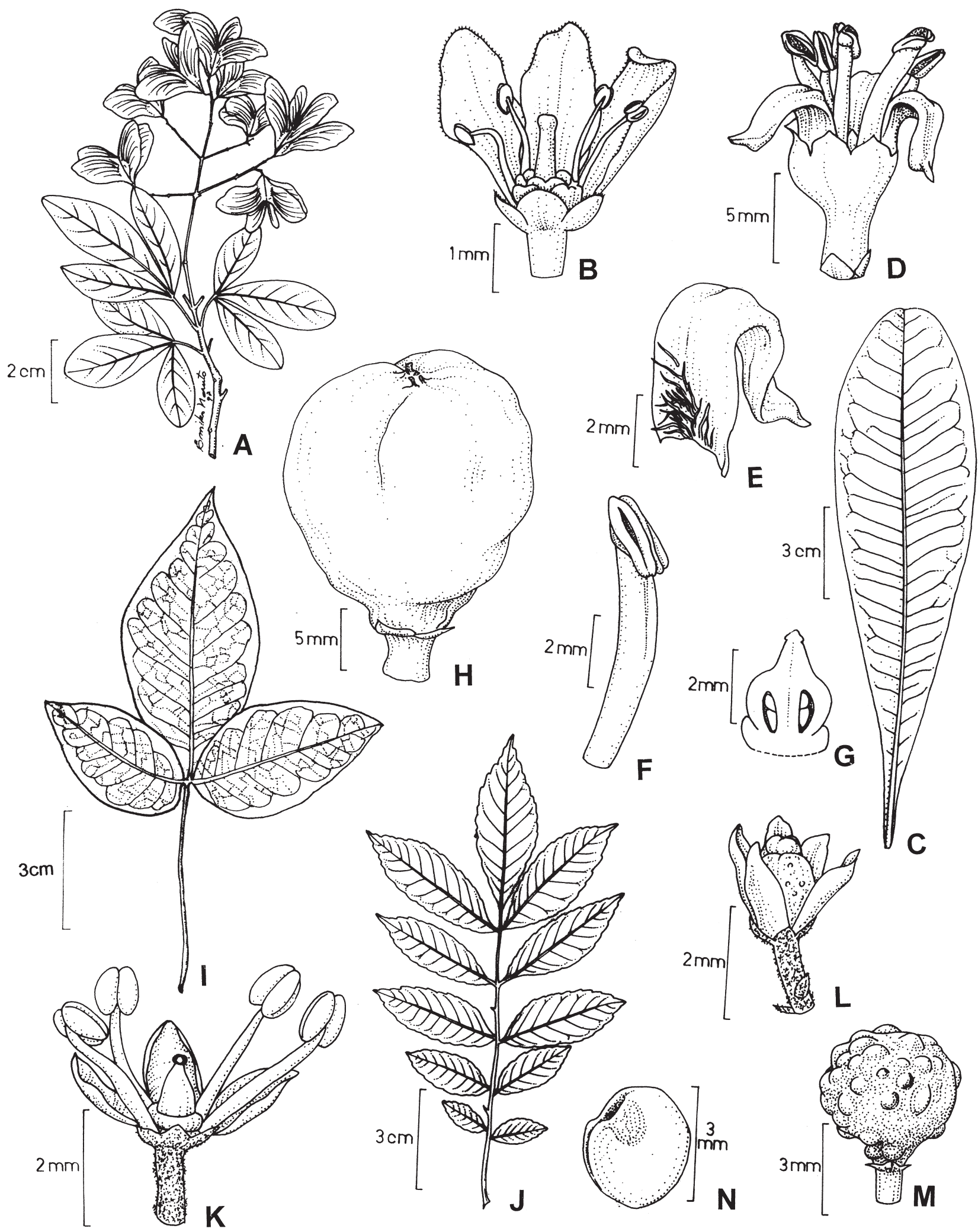

Fig. 2. RUTACEAE: A-B. Helietta glaziovii: A. Ramo frutífero; B. Flor da qual foram removidas duas pétalas. C-H. Hortia brasiliana: C. Folha; D. Flor; E. Pétala, vista lateral, com tufo de tricomas na base interna; F. Estame; G. Gineceu em corte longitudinal, e disco; H. Baga imatura. I. Spiranthera odoratissima, folha. J-N. Zanthoxylum rhoifolium: J. Folha aculeada; K. Flor estaminada sem duas pétalas e um estame, note pistilódio e disco; L. Flor pistilada; M. Fruto antes da deiscência; N. Semente. 
rais, e Serra de Catolés na Chapada Diamantina, Bahia, habitando matas ripárias e vegetação arborescente entre grandes afloramentos rochosos. Algumas coleções antigas atribuídas ao Rio de Janeiro são duvidosas quanto à confia- bilidade da procedência (ver Pirani 1998). Em Grão-Mogol, ocorre nas matas ripárias das margens dos rios Itacambiruçu e Ribeirão. Floresce em janeiro e fevereiro, e frutifica de janeiro a abril.

\section{Hortia Vand.}

Árvores ou arbustos; folhas alternas, simples. Inflorescência em panícula corimbiforme terminal, multirramosa. Flores bissexuadas, 5-meras, actinomorfas; cálice cupuliforme, coriáceo; pétalas valvares, livres, carnosas, oblongas, apiculadas, com denso tufo de tricomas longos na base interna; estames 5, filetes carnosos, anteras oblongas, conectivo espessado; disco 5-lobado; ovário globoso, 5-lobado, 5-locular, óvulos 2 por lóculo, superpostos; estilete cônico, curto, 5-lobado. Fruto baga coriácea subglobosa, 5-locular, poucas sementes.

\subsection{Hortia brasiliana Vand. ex DC., Prodr. 1: 732.1824.}

Árvore até $9 \mathrm{~m}$ alt. Folhas subcoriáceas, glabras, lustrosas, oboval-oblongas a oblongas, ápice obtuso ou truncado ou curto-acuminado, margem inteira revoluta, base muito atenuada, com glândulas translúcidas dispersas pela lâmina, nervação broquidódroma saliente, 10-24 cm compr., 2,5-7 cm larg.; pecíolo espessado na base. Inflorescências terminais amplas, multifloras, com eixos purpúreo-acastanhados, transversalmente fissurados; cálice cupuliforme vináceo; pétalas rosadas, reflexas, apiculadas, 5-7 mm compr., com um tufo de tricomas alongados na porção mediana-basal; estames 6-8 mm compr.; filetes espessados, róseos, inseridos no disco hipogínico; anteras versáteis, creme; gineceu glabro, ca. $2 \mathrm{~mm}$ compr., estigma diminuto. Baga subglobosa, verde, ca. $3 \mathrm{~cm}$ compr., com numerosas glândulas oleíferas e poucas sementes. (Fig. 2. C-H)
Cordeiro et al. CFCR 10161 (SPF); Lima et al. 1012 (RB); Lobão et al. 605 (K, NY, RB, SPF); Pirani \& Mello-Silva CFCR 10854 (SPF); Pirani et al. CFCR 852 (SPF); Prado et al. CFCR 12059 (SPF).

Bahia, Minas Gerais, Espírito Santo e Rio de Janeiro, desde as matas pluviais costeiras até as matas do interior. Em Grão-Mogol, habita as matas de encosta e dos topos de elevações. Floresce de abril a julho; frutos foram encontrados em setembro.

Conforme demonstraram Groppo et al. (2005), até recentemente esta espécie vinha sendo tratada erroneamente como Hortia arborea Engl., enquanto o binômio H. brasiliana vinha sendo aplicado -também erroneamente- para denominar uma outra espécie dos campos e cerrados do Planalto Central (H. oreadica Groppo, Pirani \& Kallunki).

Nomes populares: lima d'anta, limão-bravo, limão-de-cutia.

\section{Spiranthera A.St.-Hil.}

Árvores ou arbustos. Folhas alternas, 3-folioladas, com pontuações translúcidas (glândulas oleíferas). Inflorescência um tirsóide terminal ou subterminal, geralmente corimbiforme, longo-pedunculado. Flores bissexuadas, 5-meras, actinomorfas; pétalas livres, lineares, subcarnosas; estames 5, alternipétalos, anteras oblongas, espiraladamente torcidas após a antese; ovário 5-carpelar, sobre um ginóforo colunar circundado na base pelo disco intra-estaminal anular; óvulos 2 por lóculo, superpostos. Fruto esquizocarpo com 1-2(5) mericarpos foliculares, carenados dorsal e ventralmente, transversalmente rugosos; semente 1 por folículo.

6.1. Spiranthera odoratissima A. St.-Hil., Bull. Sci. Soc. Philom. Paris sér. 3, 10: 130. 1823.

Arbusto 0,5-2 m alt. Pecíolo semicilíndrico, rugoso, 3-5 cm compr.; folíolos curto-peciolulados, ovados a lanceolados, ápice longo-acuminado, margem revoluta, base obtusa a subcordada, assimétrica nos folíolos laterais, face adaxial lustrosa e glabrescente, a abaxial opaca e pubérula a glabrescente, 3-7,5 cm compr., 2-4 cm larg., nervuras laterais bem salientes na face abaxial. Inflorescência um mono- ou di- a pleiotirsóide ereto, paucifloro, 6-15 cm compr., pubérulo. Cálice cupuliforme, 5-dentado; pétalas 2-3,5 cm compr., alvas a creme, denso-pubescentes; ginóforo seríceo; ovário tomentoso; estilete 3-6 cm compr. Mericarpos conchiformes, com uma apófise dorso-apical ascendente, esparsamente pubescente, ca. 1,5 cm compr. (Fig. 2. I)

Pirani et al. 5366 (SPF); Souza et al. 25876 (ESA, SPF).

Espécie distribuída pelos cerrados e campos do Brasil Central (Rondônia, Mato Grosso, Pará, Maranhão, Piauí, Goiás, Bahia e Minas Gerais) e também na Bolívia. Em Grão-Mogol, foi coletada no cerrado, com flores em março e julho, e frutos em julho. 


\section{Zanthoxylum L.}

Árvores ou arbustos, aculeados ou inermes. Folhas alternas geralmente pinadas, com pontuações translúcidas (glândulas oleíferas). Inflorescência terminais, axilares ou laterais (ramifloras). Flores unissexuadas em plantas dióicas, 3-5-meras, (mono ou) diclamídeas; pétalas livres, imbricadas; estames isômeros, alternipétalos, reduzidos a estaminódios ou ausentes nas flores pistiladas; disco intra-estaminal anular ou estipitado; gineceu com 1-5 carpelos unidos apenas pelos estiletes, reduzido a pistilódio nas flores estaminadas, estilete lateral, estigma capitado, 2 óvulos por lóculo. Fruto folículo ou esquizocarpo com mericarpos foliculares, seco, semente 1 por carpelo.

\subsection{Zanthoxylum rhoifolium Lam., Encycl. 2(2): 39. 1786.}

Arvoreta até $7 \mathrm{~m}$ alt., tronco aculeado. Folhas pari ou imparipinadas, aculeadas ou não, com tricomas estrelados; folíolos 10-20, opostos a subopostos, cartáceos, subsésseis, elípticos a oblongo-elípticos, ápice obtuso ou agudo, margem crenada, com numerosas glândulas translúcidas muito odoríferas, 2-5 cm compr., 0,7-2 cm larg. Inflorescências terminais e axilares em tirsos piramidais, multifloros, estrelado-pilosos; flores 5-meras, creme-esverdeadas; pétalas glabras; estames 5, livres, reduzidos a estaminódios deltóides nas flores pistiladas; disco anular glabro; ovário subgloboso, glabro, com estigma subséssil discóide, unilocular, 2 óvulos colaterais, reduzido a pistilódio cônico nas flores estaminadas. Folículo subgloboso, vináceo a marrom, ca. 5 mm compr., com numerosas glândulas oleíferas salientes, 1 semente negra, pendente pelo funículo na deiscência do fruto. (Fig. 2. J-N)

Pirani et al. CFCR 12656 (SPF).

América do Sul, ocorrendo em ambientes diversos, mas principalmente abertos, por ser heliófila. Em Minas Gerais, é freqüente em áreas perturbadas, capoeiras e orlas de matas. Em Grão-Mogol, é pouco comum, tendo sido coletada em área de transição cerrado-mata perturbada, frutificando em dezembro.

Nome popular: mamica-de-porca, maminha-de-cadela. 
